\title{
Incisal Morphology of Southern Chinese
}

\author{
John Y.K. Ling and Ricky W.K. Wong* \\ Department of Orthodontics, University of Hong Kong, Hong Kong
}

\begin{abstract}
Aim: To investigate the dental morphology of incisors of the Southern Chinese and compare these with studies in different populations.

Materials and Methods: The dental morphology of study casts of an unselected sample from a 12 year old Hong Kong Oral Health Survey of 12 year old children ( $n=459 ; 295$ boys and 164 girls) were studied.

Results: The moderate types of shovel-shaped central incisors were prevalent in the Southern Chinese, whereas the pronounced type of shovel-shaped incisors were more prevalent in the Taiwan Chinese.

Conclusion: The Southern Chinese shows a lesser degree of shoveling than the other Chinese populations.
\end{abstract}

Key Words: Dental morphology, Southern Chinese.

\section{INTRODUCTION}

It is generally believed that the numerous morphologic characteristics of the teeth are genetically determined [1,2]. Detailed description and study of these traits could provide valuable information regarding phylogeny of man and distinctions between races and subraces [1, 3-12]. Features of morphology which closely reflect genetic structure should be examined in determining the evolutionary (phylogenetic) relationships of populations and in establishing taxonomies that reflect these relationships [12]. Although tooth morphology may be an indicator of genetic distances between populations, it should be viewed with caution [11].

\section{SHOVEL-SHAPED INCISORS}

The term "shovel-shape" was first introduced by Miihlreiter in Germany, 1870. The resemblance to a shovel results from the combination of a concave lingual surface and elevated marginal ridges of the incisor teeth [3].

Marginal ridges, also called dentales, are present usually in the maxillary incisors and are relatively rare on the mandibular incisors. These ridges are pronounced in the incisors of Mongoloids [3, 10, 13]. In a further study Hrdlicka [4] found a high percentage of shovel-shaped incisors in Chinese, Japanese, Eskimos and American Indians, but a low percentage in Negroes and American Whites. Other workers have substantiated Hrdlicka's observations [1, 5, 6, 8, 10, 1416]. This dental trait is now considered to be a characteristic for populations of Mongoloid stock. The degree of shoveling was also used to differentiate ethnically between the Pueblo Indians and the Plains Indians [17]. Shovel-shaped incisors usually occur bilaterally in the maxillary incisors but can occasionally be seen on the mandibular incisors [3].

*Address correspondence to this author at the 2/F, Orthodontics, Prince Philip Dental Hospital, 34 Hospital Road, Sai Ying Pun, Hong Kong, China; Tel: 852 28590554; Fax: 852 25593803; E-mail: fyoung @hkucc.hku.hk
Lasker [6] compared the frequency distribution of shovel shaped incisors between Chinese born in China and Chinese born in the United States. No difference was found between these two groups in the frequency distribution of the variation of shoveling, which seems to indicate that altering the environment will not influence the expression of a shovel trait. Marked forms of shoveling are observed in the maxillary rather than in the mandibular incisors and more frequently in the permanent than in the primary incisors $[3,8]$.

\section{CLASSIFICATION OF SHOVEL-SHAPED INCISORS}

Most studies have made use of Hrdlicka's subjective scale [3] for grading the degree of shovel shape incisors:

No shovel -

no perceptible trace of rim and fossa or in which traces of these were so faint or imperfect as not to deserve special characterization.

Trace shovel - distinct traces of the enamel rim but which could not be classed yet as semi-shovel.

Semi-shovel - the enamel rim was distinct but the enclosed fossa was shallow.

Shovel - the enamel rim with the enclosed fossa were well developed.

Dahlberg and Mikkelsen [18] developed a device for measuring the distance between the highest part of the rims and the deepest point in the fossa. Some studies, for example Moorrees [1], added a fifth category for "markedly" shovelshaped incisors. Ridge formation was also observed on the labial surfaces of maxillary incisors in what Dahlberg and Mikkelsen [18] and Dahlberg [5] have called double shovelshaped incisors.

An eight-grade classification ranging from absence to pronounced marginal ridges was developed by Scott [19] to collect data on the degree of shoveling expression in Southwest Indians. As shoveling was effectively invariant (100\%) 
in American Indians, the data were dichotomised for shoveling (grades 1-3, unaffected slight to moderate shoveling) and pronounced shoveling (grades 4-7, affected) in a later study by Scott and Dahlberg [17]. Turner and coworkers [20] employed a seven-grade scale for shoveling that provides finer subdisions of Hrdlicka's semi- and full shovel categories.

\section{INTERTRAIT ASSOCIATION OF SHOVEL-SHAPED INCISORS}

The correlation in total incidence between maxillary central and lateral incisor shoveling has long been noted on a population basis [3]. Few authors have analyzed this trait on an individual level with a test for association. Shoveling of the maxillary central incisor is strongly associated with trait expression on the three other incisors, namely the maxillary lateral, mandibular central and lateral incisors. The shoveling association indicates a field common to both jaws. Because of differences in form between the corresponding teeth in the maxilla and mandible, the field effect is often discussed in terms of upper and lower field districts. The lower incisor field is usually noted as exceptional because of the greater variability regarding agenesis and size exhibited by the lower central incisor [5]. This contrasts with the great variation of the upper lateral incisor

There may be a systematic error in the classification of the shovel-shaped central and lateral incisors. The lateral incisor has a smaller mesiodistal dimension and consequently the same depth in the shovel may be classified as a higher degree of shovel-shape [5, 10]. Suzuki and Sakai [13] noted that shovel-shape of the front teeth was not an independent characteristic but the final phenotype caused by the relative or absolute degree of development of the morphological variation of many characteristics present in the lingual surface of anterior teeth. Lee and Goose [21] suggested multifactorial inheritance of shoveling and Blanco and Chakraborty [22] calculated that about $68 \%$ is due to heredity

\section{SEX DIFFERENCES OF SHOVEL-SHAPED INCI- SORS}

The presence of labial ridges was not associated with the more pronounced degree of shoveling of the lingual surfaces. Sexual dimorphism is consistently present in the shoveling of incisors, with males showing a preponderance of the more pronounced degrees [23]. Hrdlicka [3] indicated that the shoveling trait of incisors was more frequently found in Chinese females, but other investigators found no sex difference in the degree of expression of the shovel trait $[10,15]$.

\section{POPULATION DIFFERENCE IN SHOVEL-SHAPED INCISOR}

As in all other populations of predominantly Mongoloid stock, the occurrence of shoveling of the maxillary incisors is very high in the Chinese $[3,24]$. The subjects in Hrdlicka's [3] sample were from Peking and other northern provinces of China. By studying the dentition of peoples with Mongoloid affinities, other investigators observed a high frequency of shovel-shaped incisors and thus confirmed Hrdlicka's observations $[1,5,6.8,18,24]$ reported $70.1 \%$ of shovel, $29.1 \%$ of semi-shovel, $0.8 \%$ of a trace of shovel and $0 \%$ of nonshovel maxillary lateral incisors in Chinese families living in
Liverpool. Similar findings were found for the central maxillary incisors.

In Hrdlicka's [3] study, 'the Hawaiian male, who represented a high percentage of white admixture with Mongolian, Melanesian and Polynesian races, had a much lower frequency $(42.9 \%)$ than did the Japanese male $(77.9 \%)$. The American Indian had a high frequency of $67 \%$, while the white male had the lowest $(1.4 \%)$.

In the Aleuts [1] and East Greenland Eskimos [25], the lateral incisors showed a higher percentage of marked shoveling than the central incisors. This may be because the lateral incisor is narrower mesiodistally than the central incisor and is giving one the impression of a more pronounced shovel, while in reality, the ridge can be of the same height [5].

The North American Indians have the highest frequencies of shovel-shaped incisors reported of about $100 \%[3-5,10$, $18,26,27]$.

In Caucasoid races, moderate and shovel forms of incisors are very rare, with a high frequency of non-shovelshaped incisors [3, 10]. However, Lasker [7] found that up to 40-50 per cent of the maxillary incisors in American whites are shovel-shaped.

Differences in frequency and variations in degree of shovel-shaped incisors within racial groups are evident from a study of Chinese from different geographical areas [6], in the different tribes of North American Indians [3], South Americans [28] and Bantus of South Africa [10].

\section{PEG-SHAPED AND BARREL-SHAPED LATERAL INCISORS}

A peg-shaped tooth was defined by Grahnen [29] as any reduction in mesiodistal crown diameter in a gingivo-incisal direction. The frequency distribution of the peg-shaped maxillary lateral incisors reported is variable in different studies, it ranged from $0.5 \%$ to $3.4 \%$. These differences may be due to lack of definite criteria for describing this tooth or it may be a true racial difference. Peg-shaping of the permanent maxillary lateral incisors was found to be more frequent in females than in males [29-31]. Only a few reports have noted a definite predilection for sidedness in the case of the unilateral peg-shaped lateral incisor [3, 30]. Meskin \& Gorlin [32] disclosed a 2 to 1 ratio for left sided peg-shaped incisors.

The barrel shape anomaly in maxillary lateral incisors is generally considered to be a more pronounced manifestation of a thickened or elevated cingulum found on the gingival aspect of lingual surfaces of some upper incisors. The excessive structural bulge extending almost to the incisal edge gives the appearance of a premolar. It is found in Mongoloid populations in about the same frequency as the peg shaped incisor is found in other racial groups [26, 27].

\section{EXTRA CUSPS ON INCISORS - TALON CUSPS}

Talon cusp is a cusp-like hyperplasia arising from the cingulum area of the maxillary or mandibular teeth. This dental morphology was first described as a "process of hornlike shape, curving from the base down to the cutting edge" on the palatal surface of the left maxillary central incisor of a 
female patient. Schulze [33] referred to the accessory cusp as a "T- form or, if lower, a Y-shaped contour"

Mellor and Pipa [34] described seven cases of permanent incisors affected and coined the term talon cusp because it resembles an eagle's talon in shape. They reported that talon cusp might cause problems of aesthetics, increased caries susceptibility, occlusal trauma and even mistaken identity for a supernumerary tooth. In addition, irritation of the tongue during speech and mastication, displacement of teeth, advanced attrition causing pulpal exposure or periapical pathologies have been reported [35, 36]. Talon cusps were reported to be associated with Mohr syndrome and RubinsteinTaybi syndrome [37, 38].

'Southern Chinese' are defined as those Chinese whose ancestors originated from provinces south of the Yangtze River and they speak different dialects from the northerners. There is no study about the prevalent of various dental morphologies in this population.

The aim of our study is to investigate the dental morphology of incisors of the Southern Chinese and compare these with studies in different populations.

\section{MATERIALS AND METHODS}

Dental study casts ( $\mathrm{n}=459 ; 295$ boys and 164 girls) were obtained as part of a multi-disciplinary survey of crosssectional, randomly selected sample of 1247 12-year-old Chinese children from the Oral Health Project in Hong Kong [39-40]. Teeth found to be carious, missing, restored at the measurement landmark, hypoplastic, worn or malformed or orthodontically moved were excluded from the present investigation. Damaged casts which made the measurement data questionable were also omitted. Only study casts with permanent dentition were included in the study.

Shovel-shape and other related traits affecting the central and lateral incisors were recorded.

In this study, Snyder's subjective scale was used for grading the degree of shovel-shape (Fig. 1) Abnormal morphology of the incisors such as peg-shaped or barrel-shaped incisors, the presence of talon cusp, hypoplastic teeth and unclassified malformations (Fig. 1) were all recorded as code below:
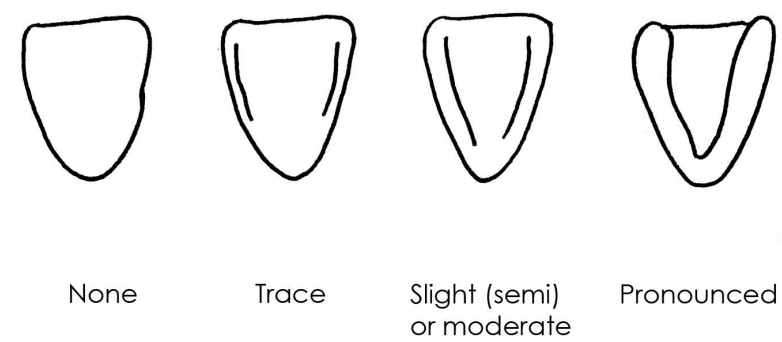

$$
\text { Trace }
$$

Slight (semi) or moderate

Pronounced

(2)

(3)
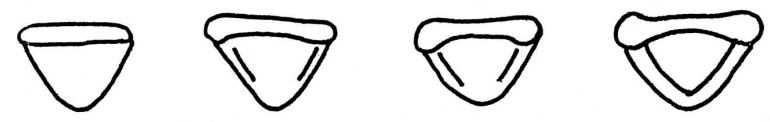

\begin{tabular}{|c|c|}
\hline Code & Trait \\
\hline 0 & Absence of shovel \\
\hline 1 & Faint shovel \\
\hline 2 & Moderate shovel \\
\hline 3 & Pronounced shovel \\
\hline 4 & Hypoplastic \\
\hline 5 & Peg-shaped \\
\hline 6 & Barrel-shaped \\
\hline 7 & Talon cusp present \\
\hline 8 & Malformed, unclassified as above \\
\hline 9 & Undetermined \\
\hline
\end{tabular}
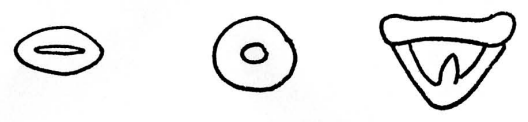

Occlusal surface

\section{RESULTS}

Table 1 shows frequencies of shovel-shaped incisors, peg-shaped and barrel-shaped lateral incisors and talon cusps. No statistical significant differences were found between the left and right sides in both sexes and therefore the results were pooled. Pronounced shoveling of maxillary central and lateral incisors occurred more frequently in males (7 $\%)$ than females $(3 \%)$. Pronounced shoveling was rare in mandibular incisors of both sexes. Moderate shoveling of mandibular incisors occurred more frequently in males $(2 \%)$ than females $(1 \%)$. One percent of maxillary incisors and thirteen percent of mandibular incisors had no Shovelshaped trait in both sexes. Peg-shaped and barrel-shaped maxillary lateral incisors occurred in one percent of the sample.

Pronounced shoveling occurred more frequently in maxillary lateral incisors (27\% and $22 \%$ ) than maxillary central incisors (7\% and $3 \%$ respectively). Talon cusp occurred only once in the male maxillary central incisor and with a frequency of $2 \%$ for male maxillary lateral incisor.

The anomaly dens invaginations of maxillary lateral incisors was observed in only 2 female subjects out of 459 children. No dens invagination of maxillary lateral incisors was
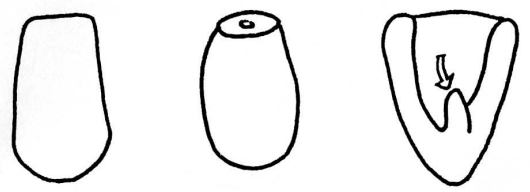

Lingual surface

(5)

(6)

(7)

Codings

surface

Fig. (1). Various morphologies of incisors and codings. 
Table 1. Prevalence (\%) of Shovel-Shaped Permanent Incisors, Peg-Shaped and Barrel-Shaped Lateral Incisors and Talon Cusps in 12 Year Old Southern Chinese Males $(n=295)$ and Females $(n=164)$

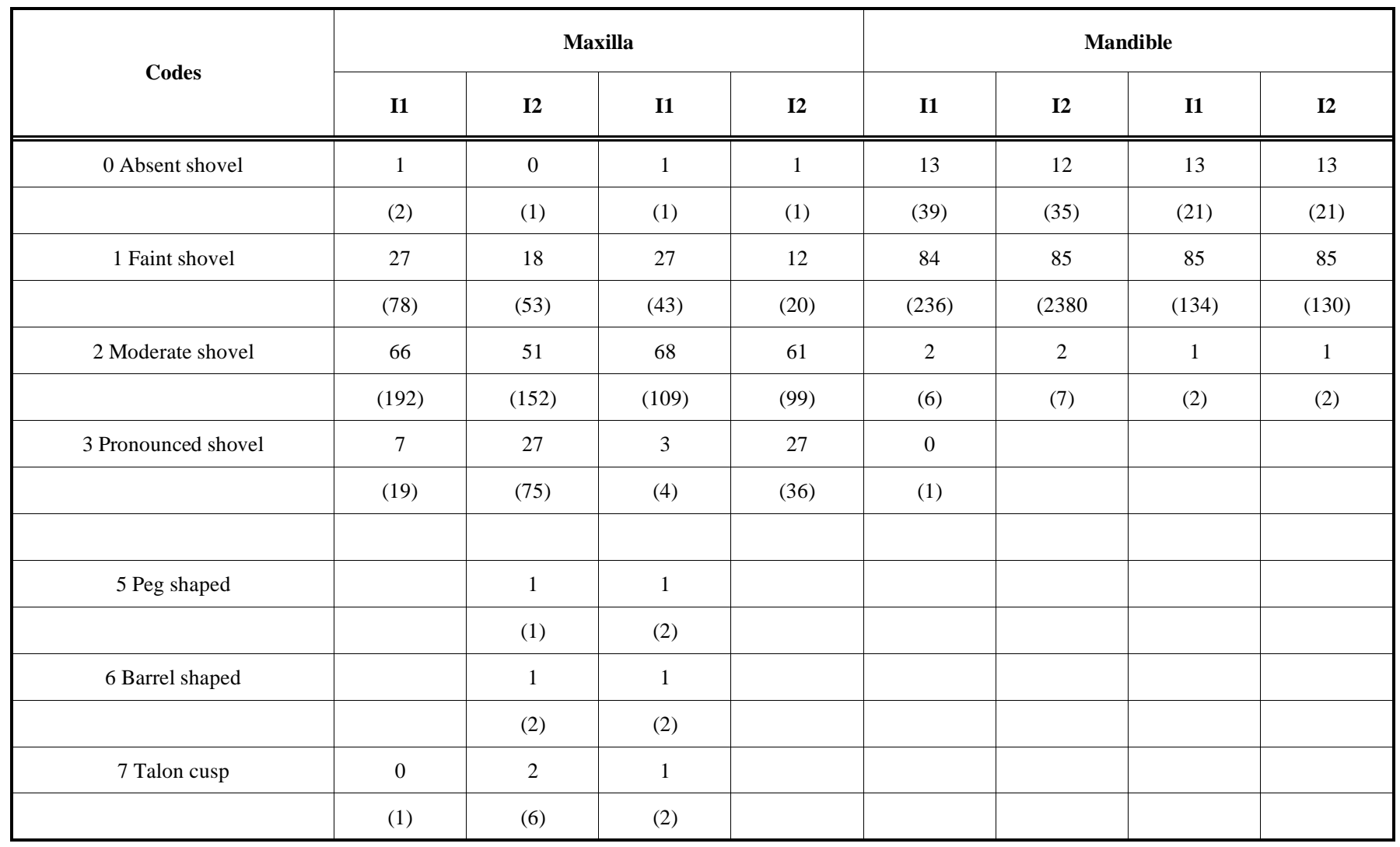

The blank spaces represent zero percentages. The number of cases in parentheses. No differences were found between the left and right sides in both sexes and therefore the result were pooled. I1, central incisors; I2, lateral incisors.

found in the male sample. The dens evagination anomaly occurred more frequently in the mandibular arch, being $4.75 \%$ and $4.27 \%$ for males and females respectively. The dens evagination anomaly occurred slightly less frequently in the maxillary arch at $2.71 \%$ and $3.05 \%$ for males and females respectively. Males were slightly more affected by the dens.

\section{DISCUSSION}

This young age group of Southern Chinese was chosen for measurement to minimize the alteration of the dental arch dimensions because of attrition, restoration or caries. Efforts were made to ensure randomization and adequate sample size to ensure validity.

The important reasons about studying the incisor morphology in Southern Chinese in this paper are related to the dental field. In clinical orthodontics, 'shovel' shaped incisors, having thick marginal ridge, do not allow orthodontic reduction of increased overjet, which is the relationship of the incisors in the anteroposterior plane; or sticking out of upper incisors, unless parts of the marginal ridges are reshaped. Therefore, the orthodontic treatment planning in those populated with increased prevalence of 'shovel' shaped incisors is different from the other populations. In clinical prosthodontics, an appreciation of shovel shaped incisor enables more natural reconstruction of crown morphology. The use of the Hrdlicka's classification allows sufficient clinical information to be conveyed to the dentists and therefore this was used in this study.

The aim of this study was to investigate the prevalence of various incisor morphologies in Southern Chinese, which were never reported before. The study was not aimed to show differences or associations between different groups, therefore statistic analyses were not performed. For the prevalence of traits with almost zero frequencies (peg shaped, barrel shaped or talon cusp), because of the extreme low prevalence, there were not valid. Further study with a larger sample size is needed.

Table 2 presents a comparison of the present study with data from the literature and shows similarities with other Mongoloid groups but obvious differences from those of the Caucasians as pointed out in the introduction section. Pima Indians have the highest frequency of pronounced shovelshaped incisors. The moderate types of shovel-shaped central incisors were prevalent in the Southern Chinese, whereas the pronounced type of shovel-shaped incisors were more prevalent in the Taiwan Chinese [41]. It could be said that the Southern Chinese shows a lesser degree of shoveling than the other Chinese population. More detailed work on the dental morphology and its variation in recent human populations appeared in the work of Scott and Turner [46].

Various studies attempt to relate the prevalence of dental morphology with different factors. Hsu et al. [47] investigated the association between the shovel and the Carabelli's 
Table 2. Comparison of Percentage Frequency of Shovel-Shaped Incisors in Various Populations

\begin{tabular}{|c|c|c|c|c|c|c|c|c|}
\hline Ethnic Group & Author (Year) & Tooth & Sex & Shovel & Semi-Shovel & Trace & None & $\mathbf{n}$ \\
\hline \multirow{8}{*}{$\begin{array}{l}\text { Southern } \\
\text { Chinese }\end{array}$} & \multirow{8}{*}{$\begin{array}{c}\text { Ling } \\
\text { (Present Study) }\end{array}$} & $\mathrm{I}^{1}$ & M & 7.0 & 66.0 & 27.0 & 1.0 & 292 \\
\hline & & & $\mathrm{F}$ & 3.0 & 68.0 & 27.0 & 1.0 & 161 \\
\hline & & $\mathrm{I}^{2}$ & M & 27.0 & 51.0 & 12.0 & 0 & 292 \\
\hline & & & $\mathrm{F}$ & 27.0 & 61.0 & 12.0 & 1.0 & 161 \\
\hline & & $\mathrm{I}_{1}$ & $\mathrm{M}$ & 0 & 2.0 & 84.0 & 13.0 & 292 \\
\hline & & & $\mathrm{F}$ & 0 & 1.0 & 85.0 & 13.0 & 161 \\
\hline & & $\mathrm{I}_{2}$ & $\mathrm{M}$ & 0 & 2.0 & 85.0 & 12.0 & 292 \\
\hline & & & $\mathrm{F}$ & 0 & 1.0 & 85.0 & 17.0 & 161 \\
\hline \multirow{8}{*}{ Taipei Chinese } & \multirow{8}{*}{$\begin{array}{l}\text { Jien S.S. } \\
(1970)[41]\end{array}$} & $\mathrm{I}^{1}$ & M & 75.9 & 20.1 & 4. & & 278 \\
\hline & & & $\mathrm{F}$ & 85.3 & 13.2 & 1.5 & & 272 \\
\hline & & $\mathrm{I}^{2}$ & M & 69.5 & 22.5 & 8.0 & & 213 \\
\hline & & & $\mathrm{F}$ & 71.2 & 21.5 & 7.3 & & 233 \\
\hline & & $\mathrm{I}_{1}$ & M & 1.4 & 5.8 & 66.1 & 26.7 & 292 \\
\hline & & & $\mathrm{F}$ & 1.0 & 7.8 & 72.4 & 18.8 & 293 \\
\hline & & $\mathrm{I}_{2}$ & M & 1.1 & 5.4 & 69.2 & 24.4 & 279 \\
\hline & & & $\mathrm{F}$ & 0.4 & 3.9 & 76.4 & 19.3 & 280 \\
\hline \multirow{4}{*}{ Chinese } & \multirow{4}{*}{$\begin{array}{l}\text { Hrdlicka } \\
\text { (1920) [3] }\end{array}$} & $\mathrm{I}^{1}$ & M & 66.2 & 23.4 & 1.8 & 7.8 & 546 \\
\hline & & & $\mathrm{F}$ & 82.7 & 12.5 & 1.0 & 3.8 & 104 \\
\hline & & $\mathrm{I}^{2}$ & M & 56.9 & 24.0 & 1.5 & 9.5 & 547 \\
\hline & & & $\mathrm{F}$ & 68.8 & 13.5 & 1.0 & 3.4 & 104 \\
\hline \multirow{2}{*}{ Japanese } & \multirow{2}{*}{$\begin{array}{c}\text { Kikuchi } \\
\text { (1967) [42] }\end{array}$} & $\mathrm{I}^{1}$ & M & 76.1 & 15.1 & 3.1 & 2.3 & 259 \\
\hline & & $\mathrm{I}^{2}$ & $\mathrm{~F}$ & 74.1 & 16.2 & 2.7 & 1.1 & 259 \\
\hline \multirow{2}{*}{ Liverpool Chinese } & Goose (1977) [24] & $\mathrm{I}^{1}$ & & 77.5 & 21.7 & 0.8 & 0 & 138 \\
\hline & Goose (1982) [43] & $\mathrm{I}^{2}$ & & 70.1 & 29.1 & 0.8 & 0 & 127 \\
\hline \multirow{2}{*}{ Eskimos } & \multirow{2}{*}{$\begin{array}{l}\text { Hrdlicka } \\
\text { (1920) [3] }\end{array}$} & $\mathrm{I}^{1}$ & & 37.5 & 47.5 & 15.0 & 0 & 40 \\
\hline & & $\mathrm{I}^{2}$ & & 57.0 & 14.7 & & & 37 \\
\hline \multirow{2}{*}{ Mongolians } & \multirow{2}{*}{$\begin{array}{l}\text { Hrdlicka } \\
(1920)[3]\end{array}$} & $\mathrm{I}^{1}$ & & 62.5 & 29.0 & 8.5 & & \\
\hline & & $\mathrm{I}^{2}$ & & & 25.0 & & & \\
\hline \multirow{4}{*}{ Aleuts } & \multirow{4}{*}{$\begin{array}{l}\text { Moorrees } \\
(1957)[1]\end{array}$} & $\mathrm{I}^{1}$ & M & 64.4 & 31.1 & 4.5 & & 45 \\
\hline & & & $\mathrm{F}$ & 60.0 & 40.0 & & & 30 \\
\hline & & $\mathrm{I}^{2}$ & M & 66.6 & 31.0 & & & 42 \\
\hline & & & $\mathrm{F}$ & 64.2 & 32.1 & 2.4 & & 28 \\
\hline \multirow{4}{*}{ Pima Indians } & \multirow{4}{*}{$\begin{array}{c}\text { Dahlberg } \\
\text { (1947) [18] }\end{array}$} & $\mathrm{I}^{1}$ & M & 96.0 & & 4.0 & & 101 \\
\hline & & & $\mathrm{F}$ & 99.0 & & 1.0 & & 125 \\
\hline & & $\mathrm{I}^{2}$ & M & 81.0 & & 13.0 & 1.0 & 93 \\
\hline & & & $\mathrm{F}$ & 81.0 & 19.0 & 7.0 & & 119 \\
\hline
\end{tabular}


(Table 2) contd....

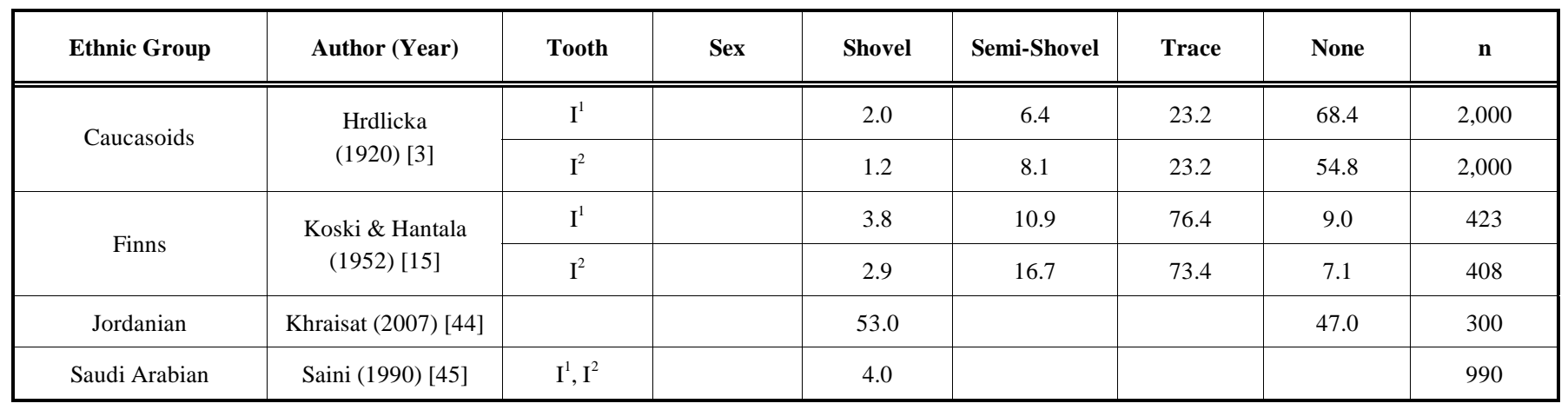

$\mathrm{I}^{1}$, upper central incisors; $\mathrm{I}^{2}$, upper lateral incisors; $\mathrm{I}_{1}$, lower central incisors; $\mathrm{I}_{2}$, lower lateral incisors; $\mathrm{M}$, male; F, female.

traits in a Chinese population. The research design investigated a Chinese population that resides in southern Taiwan. The ancestors of this Chinese population migrated to Taiwan from mainland China, mainly from Fukien and Kwangtung. The effects of sex and age on Carabelli's trait were controlled in this investigation, as was the association between tooth size and Carabelli's trait. Results show that males were more likely to have Carabelli's trait expressed on teeth than females. The buccolingual diameter of Carabelli's trait teeth was larger than that of teeth without the trait. After controlling for sex, age, and tooth size, the existence of the shovel trait increased the likelihood of having Carabelli's trait by a factor of five and a half, which is a significant effect. Further study is needed to evaluate between the association between incisor shoveling with Carabelli's trait in the Southern Chinese population.

Basdra et al. [48] investigated the putative relationships between different malocclusions such as Class III and Class II division 1, and congenital tooth anomalies. Two-hundred Class III and 215 Class II division 1 patients were examined for the presence of any of the following congenital tooth anomalies: maxillary incisor hypodontia, maxillary canine impaction, transpositions, supernumerary teeth, and tooth agenesis. Their occurrence rates were then calculated as a percentage of the total sample and were compared for statistical differences. The results revealed no statistical difference $(\mathrm{P}>0.05)$ in the occurrence rates of upper lateral incisor agenesis, peg-shaped laterals, impacted canines, or supernumerary teeth between the Class III and the Class II division 1 malocclusions. When the occurrence rate of all congenital tooth anomalies was compared between the two malocclusions, Class III subjects showed significantly higher rates (P $<0.05)$. Comparison with published surveys on general populations showed similar occurrence rates. It can be concluded from the study that subjects with Class III and Class II division 1 malocclusions show patterns of congenital tooth anomalies similar to those observed in the general population. Congenital tooth anomalies may represent another criterion for the study of malocclusion, with respect to their origin and development.

The diet for the Southern Chinese population is similar to that of the Southeast Asia and the staple diet is refined rice. This is different from the Northern Chinese population where the major carbohydrate intake is wheat. Further study is needed to investigate the association between the diet and dental morphology.

\section{CONCLUSION}

The findings on the morphology of the Southern Chinese were in accordance with other studies on the Mongoloid groups from other parts of the world. The lower prevalence of marked shovel shaped incisors was noted as compared with other ethnic groups. The frequency distribution of the moderate type of shovel shaped incisors was high (67\% in central incisor and $55 \%$ in lateral incisor). A trace of shovelshaped incisors was prevalent $(85 \%)$ in both mandibular incisors.

\section{REFERENCES}

[1] Moorrees CFA. The Aleut dentition. Cambridge, Harvard University Press, 1957.

[2] Lundstrom A. Tooth morphology as a basis for distinguishing monozygotic and dizygotic twins. Swed Med Res Council 1962; 34-43.

[3] Hrdlicka A. Shovel-shaped teeth. Am J Phy Anthropol 1920; 3: 429-466.

[4] Hrdlicka A. Further studies of tooth morphology. Am J Phy Anthropol 1921; 4: 141-76.

[5] Dahlberg AA. The dentition of the American Indian. In Dental anthropology. Papers on the physical anthropology of the American Indian. Laughlin W.S. ed. Fourth Viking Fund summer seminar. The Viking Fund, Inc., New York, 1951; 138-76.

[6] Lasker GW. Observations on the teeth of Chinese born and reared in China and America. Am J Phys Anthropol 1945; 3:129-50.

[7] Lasker GW. Genetic analysis of racial traits of the teeth. Cold Spring Harbor Symposia on Quantitative Biology, XV 1951; 15: 191-203.

[8] Tratman EK. A comparison of the teeth of people: Indo-European racial stock with the Mongoloid. Dent Rec., LXX: 1950; 70: 63-88.

[9] Moorrees CFA. Genetic considerations in dental anthropology. Genet Dent Health 1962; 101-12.

[10] Carbonell VM. Variations in the frequency of shovel-shaped incisors in different populations. In Dental Anthropology. Brothwell DR ed. Symposia of the Society for the study of human biology. Pergamon Press: New York, 1963; Vol. 5.

[11] Palomino H, Chakraborty R, Rothhammer F. Dental morphology and population diversity. Hum Biol 1977; 49: 61-70.

[12] Greene DL. Genetics, dentition, and taxomony. Univ Wyom Pub 1967; 33: 93-168.

[13] Suzuki M, Sakai T. Shovel shaped incisors among the living Polynesians. Am J Phy Anthropol 1964; 22: 65-72.

[14] Dahlberg AA. The changing dentition of man. J Am Dent Assoc 1945; 32: 676-90.

[15] Koski K, Hautala E. On the frequency of shovel- shaped incisors in the Finns. Am J Phy Anthropol 1952; 10: 127-32.

[16] Hanihara K. Dentition of the Ainu and the Australian aborigines. In D. Dahlberg, AA, Graber TM, Eds. World Anthropology: Orofacial Growth and Development. Mouton Publishers. U.S.A. 1977, Section 4, 195-200. 
[17] Scott GR, Dahlberg AA. Microdifferentiation in tooth crown morphology among Indians of the American Southwest. In Kurten ed. Teeth: Form, Function \& Evolution. Columbia Univ Press, New York, 1982; 292-7.

[18] Dahlberg AA, Mikkelsen O. The shovel-shaped character in the teeth of the Pima Indians. Am J Phys Anthropol 1947; 5: 234-47.

[19] Scott GR. Dental morphology: A genetic study of American White families and variation in living Southwest Indians. PhD. Dissertation. Arizona State Univ 1973; 1-244.

[20] Turner CG, II, Nichol CR, Scott GR. Scoring procedures for key morphological traits. In Kelley MA, Larson CS, Eds. Advances in Dental Anthropology. Wiley-Liss, New York, 1991; 13-31.

[21] Lee GTR, Goose DH. Heritability of dental occlusal variables in a family study in Liverpool, U.K. Arch Oral Biol 1972; 27: 987-9.

[22] Blanco R, Chakraborty R. The genetics of shovel shape in maxillary central incisors in man. Am J Phys Anthropol 1976; 44: 233-6.

[23] Pinto-Cisternas J. Figueroa H. Genetic structure of a population of Valparaiso. II. Distribution of two dental traits with anthropological importance. Am J Phys Anthropol 1968; 29: 339-48.

[24] Goose DH, Dahlberg AA, Graber TM. The dental condition of Chinese living in Liverpool. World Anthropology: Orofacial Growth and Development. Mouton Publishers. U.S.A., 1977; Section 4; 183-94.

[25] Pedersen PO. The East Greenland Eskimo dentition. CA Reitzels: Copenhagen, 1949.

[26] Dahlberg AA. Analysis of the American Indian dentition. In Dental Anthropology. Brothwell DR Ed. Pergamon, London, 1963; 14977.

[27] Dahlberg AA, Kirveskari P, Dahlberg T. The Pima Indian studies of the inheritance of dental morphological traits. In Kurtn ed. Teeth: Form, function and evolution. Columbia Univ Press: New York, 1982; 292-7.

[28] Devoto FCH, Arms NH, Ringuelet AS, Palma NH. Shovel-shaped incisors in a Northwestern Argentine population. J Dent Res 1968; 47: 820-3.

[29] Grahnen H. Hypodontia in the permanent dentition. Odontal Revy 1956; 7: 419-21.

[30] Brekhus PJ, Oliver CP, Montelius G. Study of the pattern and combinations of congenitally missing teeth in man. J Dent Res 1944; 23: 117-31.

[31] Brook AH. A unifying aetiological explanation for anomalies of human tooth number and size. Arch Oral Biol 1984; 29: 373-8.

[32] Meskin LH, Gorlin RJ. Agenesis and peg-shaped permanent maxillary lateral incisors. J Dent Res 1963; 42: 1476-9.
[33] Schulze C. Developmental abnormalities of the teeth and jaws. Oral Pathol 1970; 96-7.

[34] Mellor JK, Ripa LW. Talon cusp: A clinically significant anomaly. Oral Surg 1970; 29: 225-8.

[35] Mader CL. Talon cusp. J Am Dent Assoc 1981; 103: 244-6.

[36] Mader CL. Mandibular talon cusp. J Am Dent Assoc 1982; 105 : 651-3.

[37] Goldstein E, Medina JL. Mohr syndrome or oral-facial-digital. II: Report of two cases. J Am Dent Assoc 1974; 89: 377-82.

[38] Gardner DG, Girgis SS. Talon cusps: A dental anomaly in the Rubinstein-Taybi syndrome. Oral Surg 1979; 47: 519-21.

[39] Ling JYK. A morphometric study of the dentition of 12-year-old Chinese children in Hong Kong: The University of Hong Kong, 1992.

[40] King NM, Ling, BV. The dental caries status and dental treatment patterns of 12-year-old children in Hong Kong. J Dent Res 1986; 65: 1371-4.

[41] Jien SS. The Chinese dentition : II. Shovel incisors, Carabelli's cusps, groove patterns, cusp numbers, and abnormalities in morphology of the permanent teeth. J Formosa Med Assoc 1970; 69: 264-71.

[42] Kikuchi S. On the differences in the incisor shape in Japanese and European subjects. Fortschr Kieferorthop 1967; 28(3): 351-60.

[43] Goose DH, Roberts EE. Size and morphology of children's teeth in North Wales. In : Kurtn ed. Teeth: Form, Function and Evolution. Columbia Univ Press: New York 1982; 228-36.

[44] Khraisat A, Taha ST, Jung RE, et al. Prevalence, association, and sexual dimorphism of Carabelli's molar and shovel incisor traits amongst Jordanian population. Odontostomatol Trop 2007; 30(119): 17-21.

[45] Saini TS, Kharat DU, Mokeem S. Prevalence of shovel-shaped incisors in Saudi Arabian dental patients. Oral Surg Oral Med Oral Pathol 1990; 70(4): 540-4.

[46] Scott GR, Turner II CG. Geographic variation in tooth crown and root morphology. In Scott and Turner ed. The anthropology of modern human teeth. Cambridge Univ Press, Cambridge, 1997; 165 242.

[47] Hsu JW, Tsai PL, Hsiao TH, et al. Ethnic dental analysis of shovel and Carabelli's traits in a Chinese population. Aust Dent J 1999; 44(1): 40-5.

[48] Basdra EK, Kiokpasoglou MN, Komposch G. Congenital tooth anomalies and malocclusions: a genetic link? Eur J Orthod 2001; 23(2): 145-51. 